\title{
PILOT STUDY ON NAVIGATION CHANNEL REGULATION WORKS IN THE NORTH CHANNEL, YANGTZE ESTUARY
}

\author{
Min $\mathrm{Gao}^{1}$ and Dano Roelvink ${ }^{2}$
}

\begin{abstract}
It is estimated that the waterway in North Passage would not be able to meet the demand of shipping development soon and it is necessary to open a new deep navigation channel with a depth of $10 \mathrm{~m}$ in North Channel in the near future. A pilot study on the regulation of North Channel was proposed by Yangtze Estuary Waterway Administration Bureau and Prof. Dano Roelvink from UNESCO-IHE. The idea of regulating the navigation channel in North Channel was raised based on an analysis of morphological processes in this area. Multiple regulation plans were proposed, amongst which a configuration to regulate the North Channel was suggested after a study on a numerical modelling of tidal flow and morphological processes. Some suggestions were put forward for future studies.
\end{abstract}

Keywords: North Channel; navigation channel; regulation works, flow and morphological modelling

\section{INTRODUCTION}

A deep navigation channel with a depth of $12.5 \mathrm{~m}$ at the North Passage of the Yangtze Estuary was completed and opened to the world in March of 2010 (Fig. 1). The deepened channel will allow the fourth generation container ships to enter the estuary under all tidal conditions, while the fifth generation container ships and 100,000 DWT bulk carriers can use a tidal window. However, with the development of the economy in the Yangtze Valley and Yangtze Delta, it is estimated that by 2018 the capacity of the waterway at North Passage will not be able to meet the demand of a rapid increase of cargo throughput and the number of large ships passing through the Yangtze Estuary. Therefore, it is necessary to open a deep navigation channel with a depth of $10 \mathrm{~m}$ in the North Channel in the near future, to accommodate some of the vessels below 30,000 DWT that would be using the North Passage.

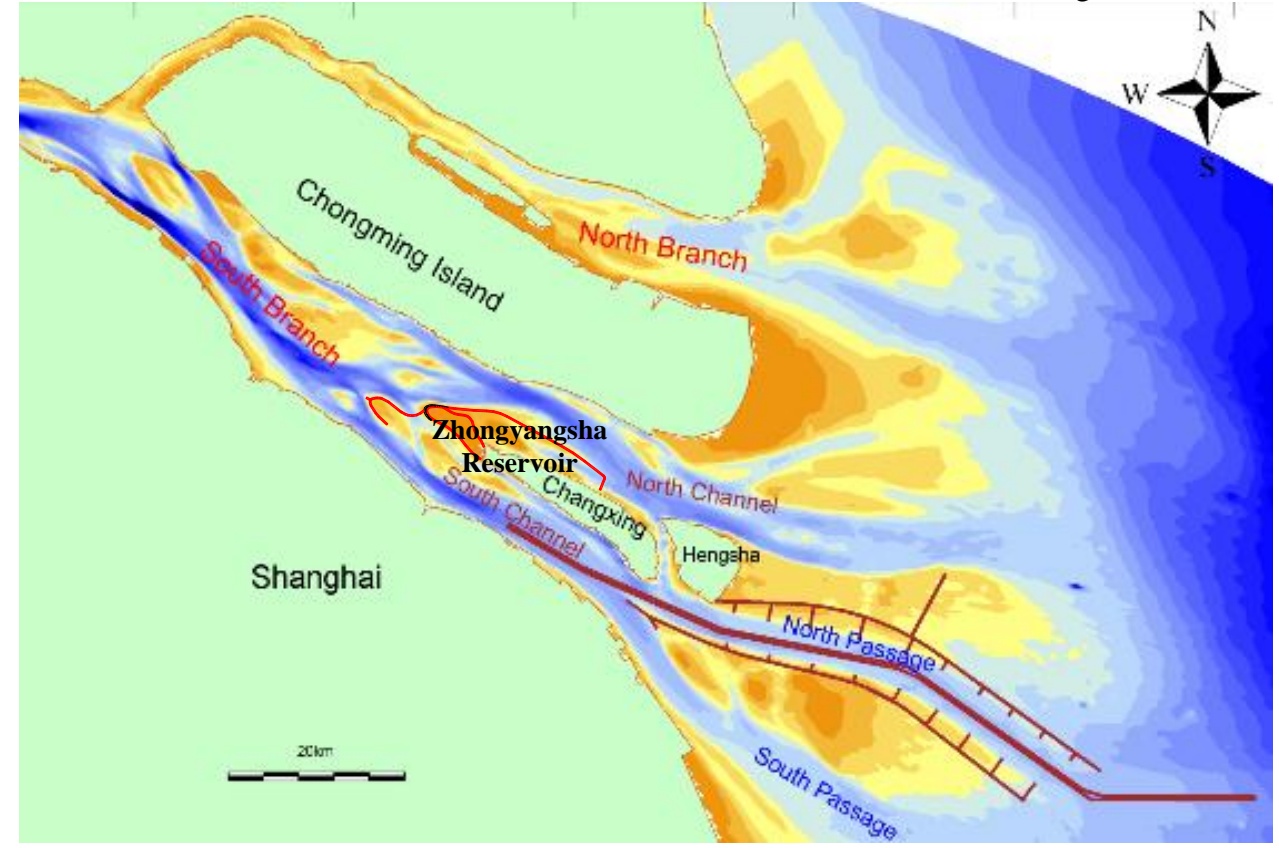

Figure 1. General layout of Yangtze Estuary

The main problem to open the navigation channel in North Channel is that the mouth bar along the North Channel is about $40 \mathrm{~km}$, where the water depth is less than 10.0m depth (Fig. 2).The idea of regulating the navigation channel in North Channel was raised based on an analysis of morphological processes in this region. Multiple regulation plans were proposed, amongst which a configuration to

\footnotetext{
${ }^{1}$ Yangtze Estuary Waterway Administration Bureau, MOT. Floor 21,48 Weihai Road, Shanghai,Zip 200003,China

${ }^{2}$ UNESCO-IHE Institute for Water Education, Deltares, Delft University of Technology, 2611 AX Delft ,The Netherlands
} 
regulate the North Channel was suggested after a study on a numerical modelling of tidal flow and morphological processes.

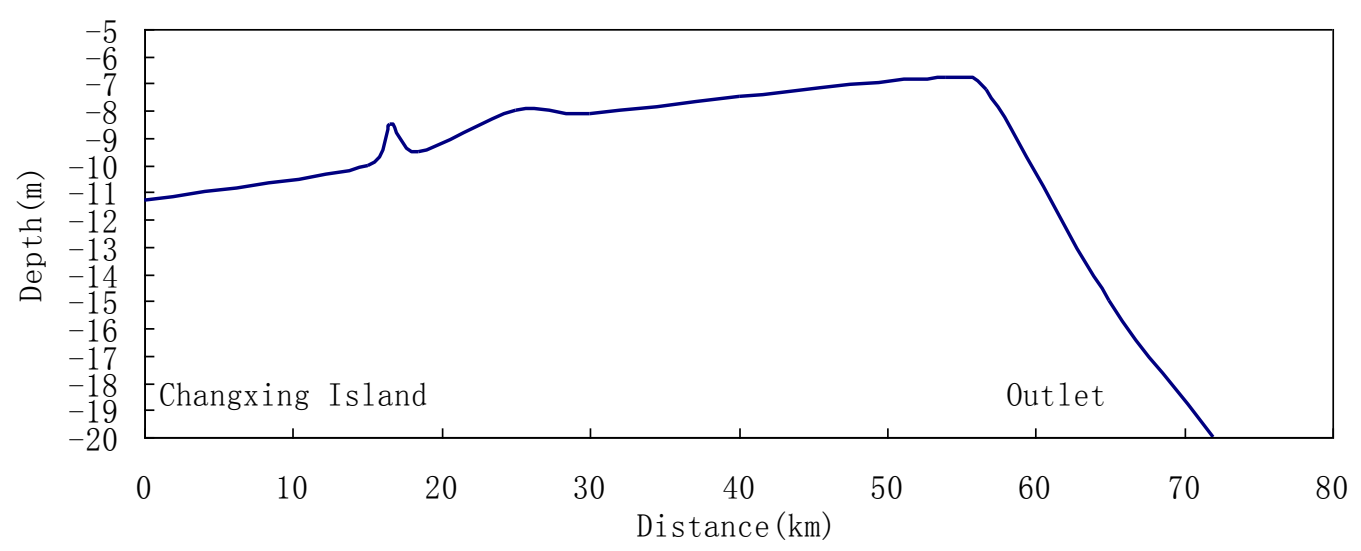

Figure 2. Longitudinal profile river bed of North Channel

\section{MORPHOLOGICAL PROCESSES}

Yangtze Estuary is characterized by ample runoff and sediment from river and strongly influenced by the tide. According to the measured data since 1950 at Datong Hydrology Station $500 \mathrm{~km}$ landward from sea, the yearly mean river runoff is about 900 billion $\mathrm{m}^{3}$ (about $28500 \mathrm{~m}^{3} / \mathrm{s}$ ) with little significant variation, while the sediment load transported from the river decreases rapidly, the average sediment load drops from 459 million t/year (1950 1989) to 344 million t/year(1990 2000) and further to 176million t/year ( 2001-2009). And 60-80\% of the total river runoff and sediment load is transported to the sea in flood season (summer season) (Fan et al. 2006). But meanwhile the sediment concentration in the estuary area does not change a lot, which may be ascribed to the fact that sediment can also be transported from the sea and local channels and shoals. The tide in Yangtze Estuary is semidiurnal. The average tidal range is $2.7 \mathrm{~m}$ at Zhongjun Gauging Station located in South Passage. Although it is median tidal range quite large tidal prism reaching 6 billion $\mathrm{m}^{3}$ in spring tide is observed.

The morphological evolution in Yangtze Estuary is governed by river runoff and tidal current under the Coriolis force, especially during the large river flood in the summer season.

\section{Historical Physical Processes}

Before 1840, North Channel was only a flood channel with many shoals scattered on it. After the big river flood in 1860, Chongming Channel formed and connected South Branch with North Channel, which made the North Channel become a main branch of South Branch.

In the following decades, with the erosion of the south bank of North Branch and the effect of circular current in the river bend, the main channel of North Channel was transformed from a straight reach to a weakly-curved reach. The fluvial process of North Channel was mainly determined by the river flow and sediment load from the upstream, as well as the evolution of the diverging area of North Channel and South Channel. Due to the erosion of the river bed and sediment supply from the upstream, the split point of North Channel and South Channel periodically deforms and moves up and down. Initially, the split point moves down with the erosion of the shoal between the two branches, and then the angle between the entrance channel and North Channel increases, resulting in decrease of the capability of delivering the runoff and sediment. During some flood seasons, the high water level gradient may cut through the shoal near upstream and form a new entrance channel connecting South Branch and North Channel, as a result of which the split point move upstream again. When there is a fluent connection between South Branch and North Channel, the deep channel in the North Channel develops, otherwise it decays.

\section{Recent Physical Processes}

- Lower river reach of South Branch

The evolution of the South Branch strongly influences the morphological process of North Channel. According to the measured data from 1999 to 2005 (Fig 3), the current-rushing point of each shoal in 
the South Branch was continuous slowly moving downward. In recent years, although the thalweg in the South Branch migrate with the recession of the shoals, the thalweg in the lower reach of South Branch keeps stable with little sway. This gives a good condition for the regulation measures. If the split point between the South Channel and North Channel is stabilized with engineering structures, the North Channel could be regulated prior to the regulation of the shoals and channels in upper South Branch.

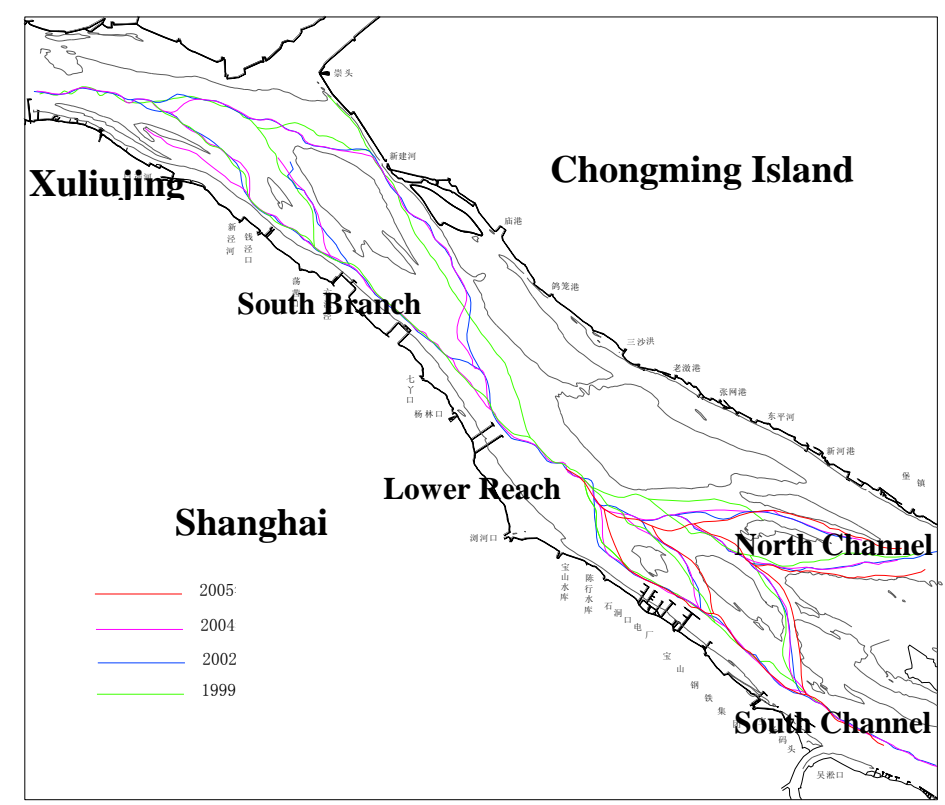

Figure 3. The Swaying of Thalweg in South Branch(1999 2005)

- $\quad$ Entrance area of North Channel

From South Branch to South Channel and North Channel, there are 6 channels and 5 shoals (Fig. 4) the evolution of these shoals and channels control the distribution of flow and sediment discharge between North and South Channel, consequently, the morphological evolution of the downstream.

The bifurcation area between North Channel and South Channel is the most complicated reach in South Branch. Baobei Channel is the main $10.5 \mathrm{~m}$-depth navigation channel. Before the regulation works in this area, there were a few unfavourable morphological changes in this river reach, which might influence the regulation in North Channel. The main ones were that the heads of Zhongyangsha Shoal, Xinliuhesha and Xinliuheshabao Shoal were continuously retreating due to erosion.

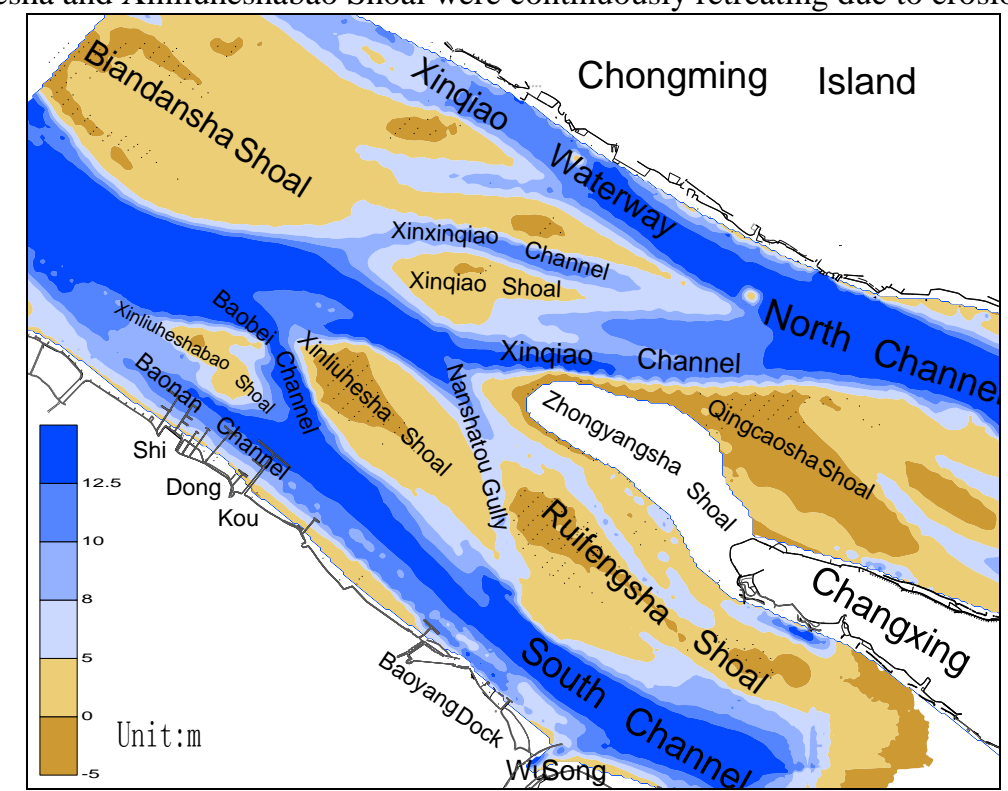

Figure 4. Layout of Bifurcation Area between North Channel and South Channel 
From 1997 to 2005, the heads of Xinliuheshabao Shoal, Xinliuhesha and Zhongyangsha Shoal were continuously retreating. As a result, the $10 \mathrm{~m}$ isobath migrated downward by $3.9 \mathrm{~km}, 3.5 \mathrm{~km}$ and $1.7 \mathrm{~km}$ respectively and the volume of shoals shrunk (Fig. 5) (Tan 2009). Such unfavourable changes resulted in dispersion and abatement of the mainstream into South Channel and the mainstream in Xinqiao Channel moved counter-clockwise. The split point between North Channel and South Channel moved downward. As a result, the Xinqiao Channel and Baobei Channel were being continuously distorted and narrowed, which cannot meet the requirement for navigation anymore. And the sediment eroded from this area would influence the morphological evolution and condition of channel at the downstream.

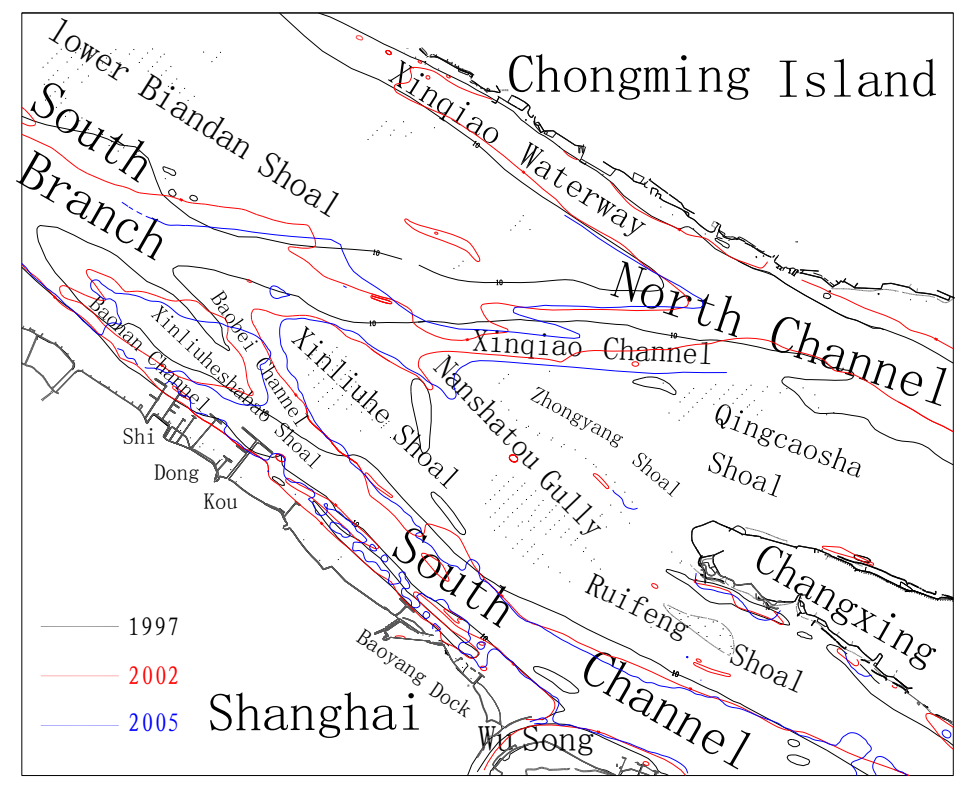

Figure $5.10 \mathrm{~m}$ isobath migration (1997-2005)

To counterbalance the unfavourable changes and stabilize the local river regime, as well as to take use of the fresh water resources, Zhongyangsha and Qingcaosha Shoal Reservoir Project and Regulation Works of Xinliuhesha Shoal Protection Works (Fig. 6) ware carried out in 2006 and completed in early 2009 with remarkable engineering effects (Tan 2009). After the above projects, the retreating speed of the heads of Xinliuhesha Shoal and Zhongyangsha Shoal decreases, the navigation condition in Baonan Channel is improved as well. The stability of bifurcation area of North Channel and South Channel are enhanced, which provides a favourable upper-boundary condition for the regulation in North Channel.

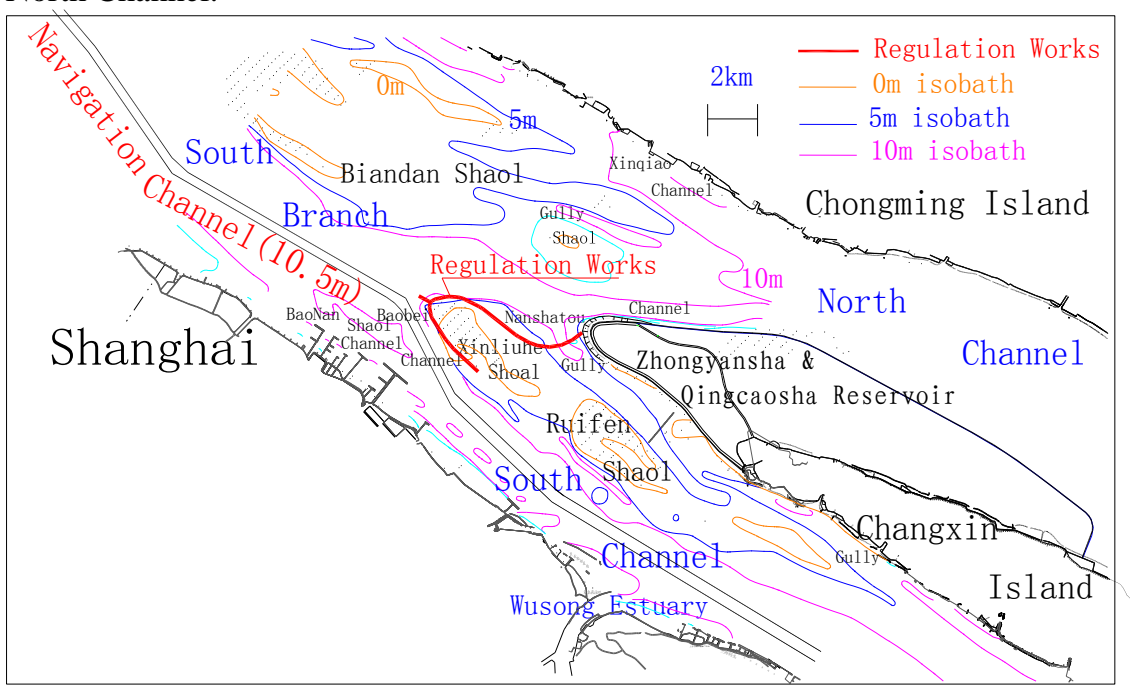

Figure 6. Regulation Works around bifurcation area of North Channel and South Channel

(Isobaths Migration 2007-2009) 
- $\quad$ Upper reach of North Channel

In the past 10 years, the shoals and channels in the upper reach keep stable with a thalweg deeper than $10 \mathrm{~m}$. After the completion of Zhongyangsha Reservoir Work and Xinliuhesha Shoal Protection Works, the river regime of upper reach of North Channel is getting more stable. In this reach a navigation channel with a draft deeper than $10 \mathrm{~m}$ will be formed without further regulating structures.

- $\quad$ Lower reach of North Channel

The lower reach of North Channel is defined as the channel from the north of Hengsha Island to the sea. In this area, the distribution rate of runoff and water exchange between South Channel and North Channel influence the development of main channel. In its evolutionary history, the more water distribution from the upstream, the better channel condition is in this area.

In this area, the ebb channel lies in the south and flood channel lies in the north. Due to the mixing of fresh and salt water, maximum turbidity forms and results in the shallow mouth bar with the minimum water depth around $6 \mathrm{~m}$. Hengsha East Shoal and Beigang North Shoal are located at the sides of the channel (Fig. 7), which form the natural border of North Channel. With the future reclamation of these two shoals, a more favourable river boundary will form and a good situation for channel regulation is anticipated. In this area, the river regime is relatively stable in recent years .

There is a small Chongming Gully which connects North Channel with North Branch and sea, which contributes some flood tidal current to North Channel and also runoff and ebb current to sea. This reduces the ebb tidal discharge through the mouth bar area. One of ideas for regulating works in North Channel is to reduce the discharge through the Chongming Gully and increase the ebb current in the lower reach to reduce the sedimentation.

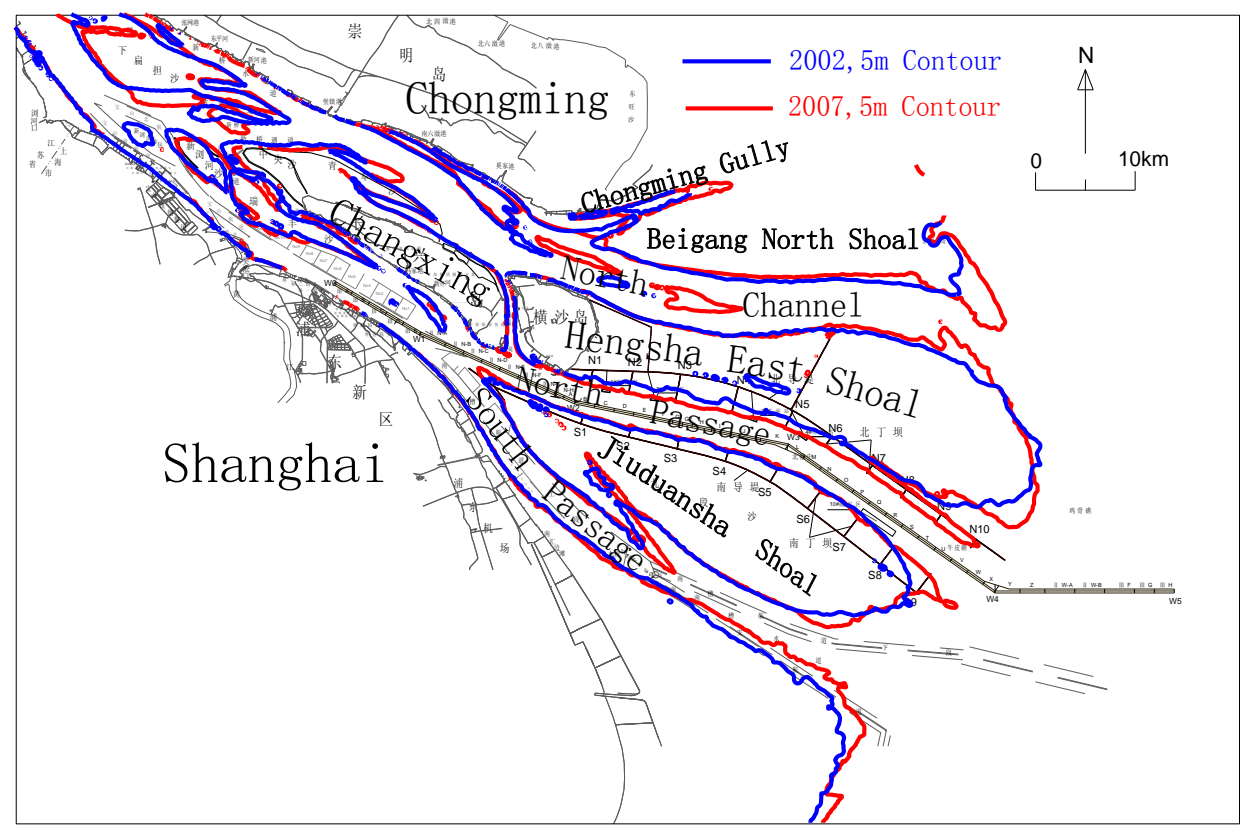

Figure 7. The variation of $5 \mathrm{~m}$ deep contours in the upper reach of the North Channel (2002 2007)

With the completion of Xinliuhesha Shoal Protection Works and Zhongyangsha \& Qingcaosha Reservoir Works, the bifurcation area at South Channel and North Channel is getting stable and the morphological processes at Baimaosha Shoal and Biandansha Shoal in South Branch have a lesser impact on the North Channel than before. Thus the North Channel can be regulated before regulating river reach at the upstream.

In the upper reach of the North Chanel, north of Changxing Island, the thalweg is stably located in north of the upstream and south of the downstream with sufficient water depth and channel width for navigation. In the middle reach, north of Hensha Island, the thalweg close to the south bank is relatively stable. Finally, in the lower reach of the North Channel, where mouth bar can be found, the fluvial processes are relatively stable with a weakly-curved river pattern but the water depth is not sufficient. 
From the viewpoint of controlling the river regime, to regulate the North Channel, it is important to use regulating structures to block or narrow the Chongming Gully connecting North Branch. In order to achieve and maintain a deep navigation channel, these regulating structures will serve to stabilize the boundary in mouth bar area, minimize the water/sand exchange between shoal and channel and improve the hydrodynamics in mouth bar area..

\section{PRINCIPLE OF REGULATION ENGINEERING PLAN}

In 2008, the strategy "Comprehensive Regulation and Development Planning of the Yangtze Estuary" was announced by Chinese Central Government, which provided a fundamental guideline for channel regulation in North Channel. All aspects in terms of water resource, flood protection, environment, ecology, fishery, recreation and harbour development etc. need to be taken into account when studying the Channel Regulation Works in North Channel.

With reference to the successful practice of channel regulation in the North Passage, channel regulation in the North Channel integrates regulating structures with channel dredging. The regulating structures would function to divert water flow and retain sediment from side-shoals, which could adjust the flow field, improve the conditions of bed load transport and reduce suspended sediment deposition. While the channel dredging would break through the mouth bar for achieving $10 \mathrm{~m}$ water depth. The back-siltation could be also effectively reduced.

A master plan of regulation works in the North Channel is proposed (Fig. 8). A submerged dike in Chongming Gully is adopted to reduce the ebb flow from the middle reach of the North Channel and to strengthen the hydrodynamics of the lower reach. In order to reduce the back-siltation in the channel of the lower reach, two long training dikes and a series of groins are proposed in order to enhance the hydrodynamics in the mouth bar area, modulate the flow field in transversal and longitudinal directions and to increase the transport capacity of suspended sediment.

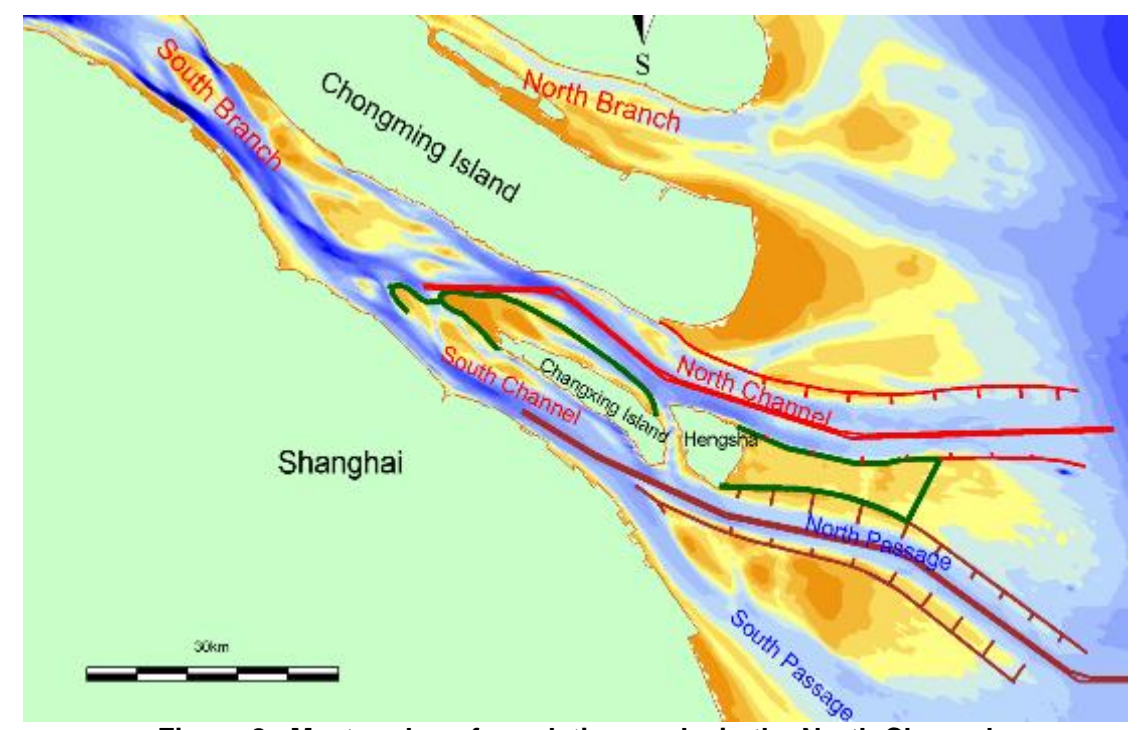

Figure 8. Master plan of regulation works in the North Channel

\section{RESULTS ANALYSIS}

A numerical model built on the platform of Delft3D was used to simulate and analyse effects of different regulation plans in the North Channel. The model domain is shown in Figure 9. An optimal configuration was selected and further simulated in a 2D-morphological model using morphodynamic evolution techniques (Roelvink, 2006).

Several configurations were proposed in view of the aspects as follows:

- Top elevation of training dikes and groins

- $\quad$ Location of dikes and groins 
- Widening rate along the channel

- Distance between groins

The configurations were summarized as Table 1. The Reference Configuration is showed as Fig.10.

Several indexes such as flow field, ebb/flood max velocity, high/low water level and ebb/flood discharge of each branch of the Yangtze Estuary are compared to choose the best configuration.

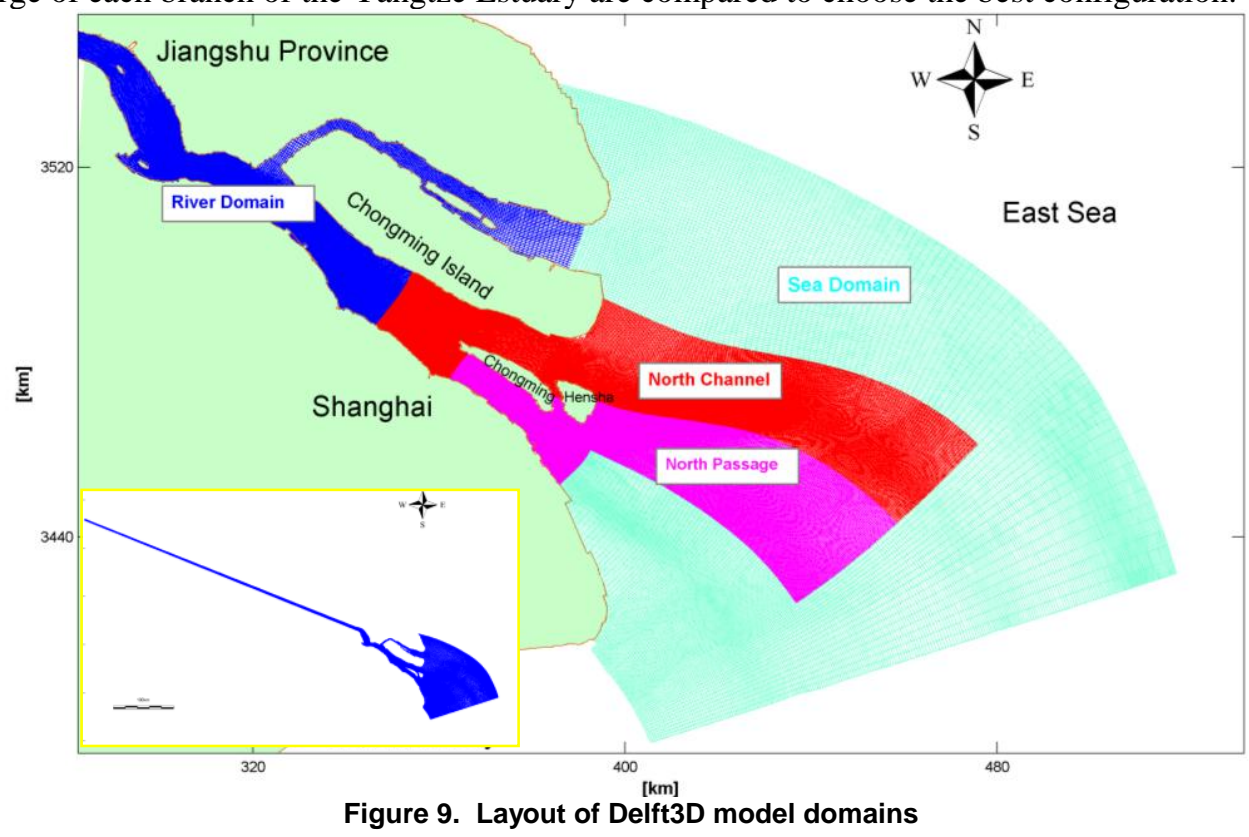

\begin{tabular}{|l|c|c|}
\hline \multicolumn{3}{|c|}{ Table 1. Reference Configuration and Proposed Configurations } \\
\hline & Top Elevation (Wusong Datum) & Widening rate \\
\hline Reference Configuration & ----- & ---- \\
Configuration 1 & $+1.0 \mathrm{~m}$ & (No groins) \\
Configuration 2 & $+2.0 \mathrm{~m}$ & (No groins) \\
Configuration 3 & $+3.0 \mathrm{~m}$ & (No groins) \\
Configuration 4 & $+2.0 \mathrm{~m}$ & $0.5 \%$ \\
Configuration 5 & $+2.0 \mathrm{~m}$ & $0.75 \%$ \\
Configuration 6 & $+2.0 \mathrm{~m}$ & $1 \%$ \\
\hline
\end{tabular}

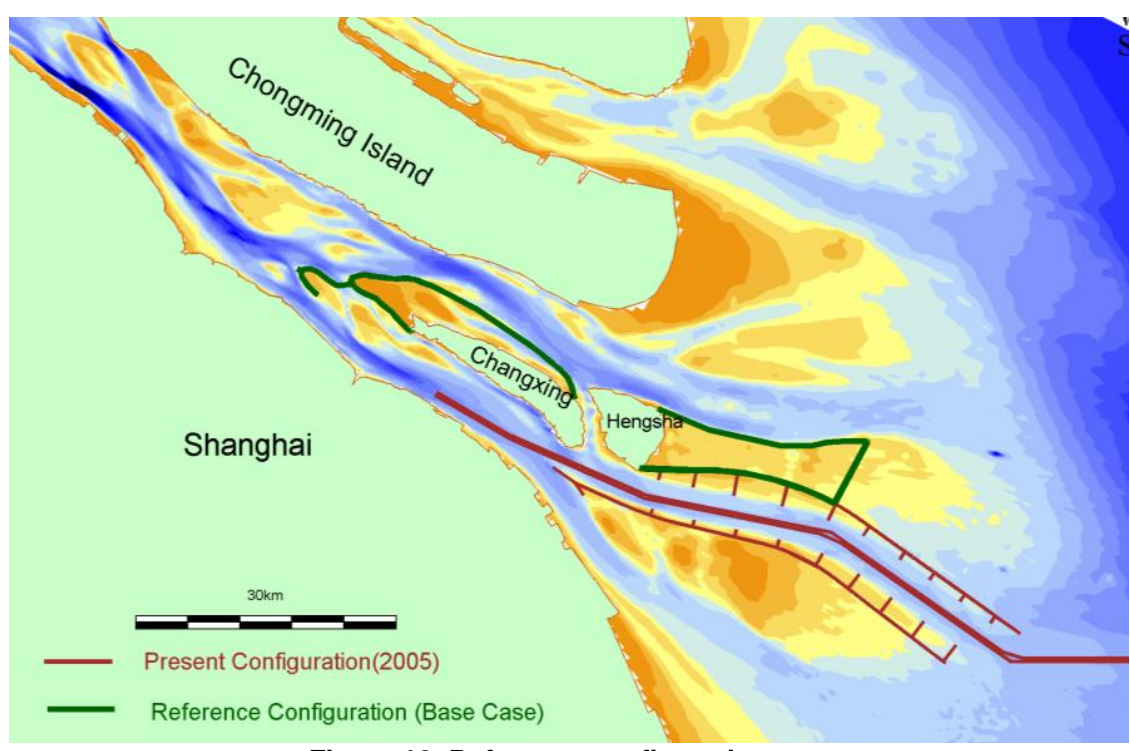

Figure 10. Reference configuration 


\section{Flow Model Simulation}

A flow model was firstly set up, then calibrated and validated with good precision. The monitoring stations inside the model are shown in Fig. 11. The tidal stations are distributed in the North Passage and North Channel, and the observation points are selectively located along the navigation channel from North Passage to South Channel and the planning channel from North Channel to South Branch.

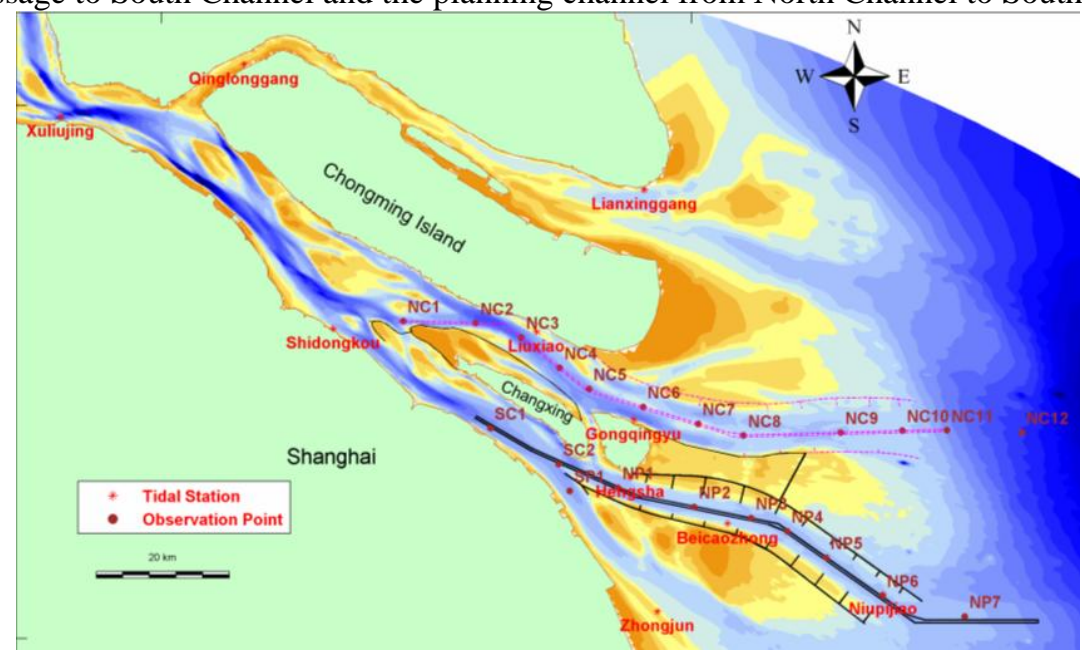

Figure 11. Position of tidal stations and monitoring stations

\section{(1) Reference Configuration and Configurations 1, 2 and 3}

As shown as Fig. 12 and Fig. 13, these projects mainly influence the tidal level at North Channel. The training dikes increase the resistance against ebb current in the lower reach of North Channel, which raises the LWL (Low Water Level) and consequently the tidal range is decreased. Compared with Reference Configuration, the tidal range in Configuration 2 decreases about $15 \mathrm{~cm}, 26 \mathrm{~cm}$ and $33 \mathrm{~cm}$ respectively at Shidongkou, Liuxiao and Gongqiyu, while the tidal level difference among the Configuration 1, 2 and 3 is relatively small (less than $3 \mathrm{~cm}$ ).

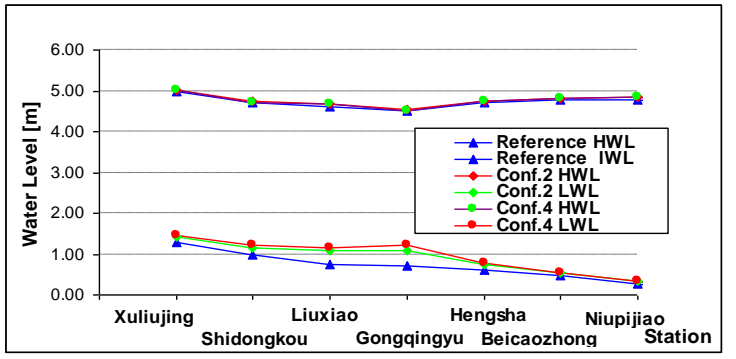

Figure 12. HWL and LWL Difference- Reference and Configuration 2 and 4

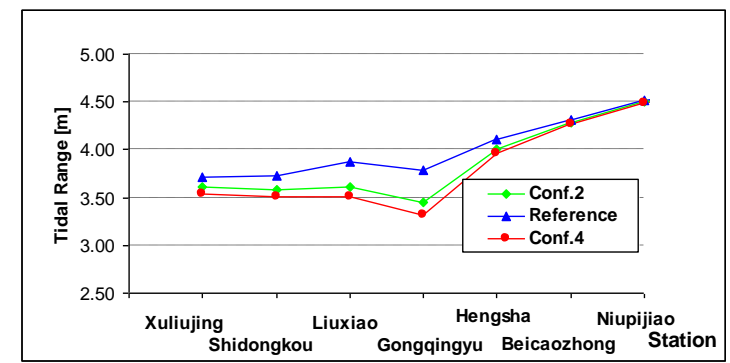

Figure 13. Tidal range Difference- Reference and Configuration 2 and 4

Regulation work in North Channel can decrease the discharge into North Channel. On average the ebb discharge in North Channel decreases by $6 \%$ compared with Reference Configuration. While the difference among Configuration 1, 2 and 3 is less than $2 \%$.

Comparing the ebb discharge and ebb maximum velocity along the North Channel (Fig. 14 and Fig. 15), the results of Configuration 1, 2 and 3 are similar: the ebb maximum velocity decreases about $0.2 \mathrm{~m} / \mathrm{s}$ in the upper reach and raises around $0 \sim 0.5 \mathrm{~m} / \mathrm{s}$ in the lower reach in the mouth bar area. Configuration 2 produces the largest ebb discharge in the mouth bar area. The engineering effect is remarkable. 


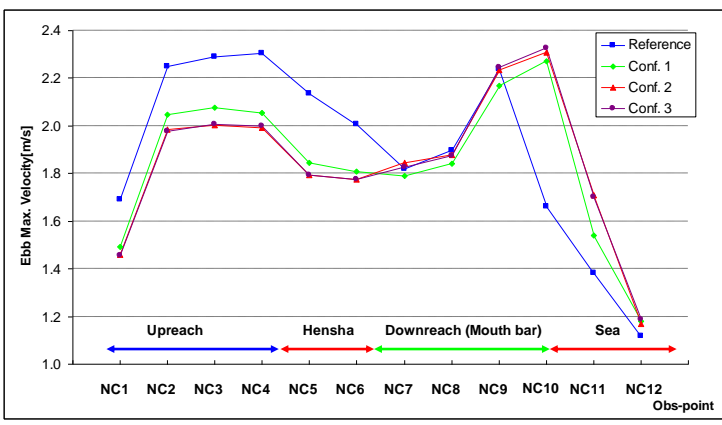

Figure 14. Ebb max. velocity along North Channel

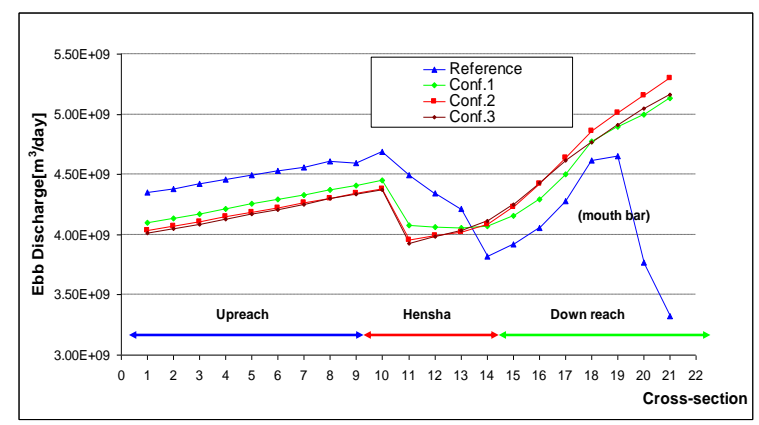

Figure 15. Ebb-discharge along North Channel

Figure 16 and Figure 17 show that after the implementation of training dikes the flow field at the downstream is changed from rotating current to reversing current and the velocity is increased. Such changes will benefit the sediment transport to the sea and improve the channel maintenance conditions when the flow direction is parallel to the navigation channel.

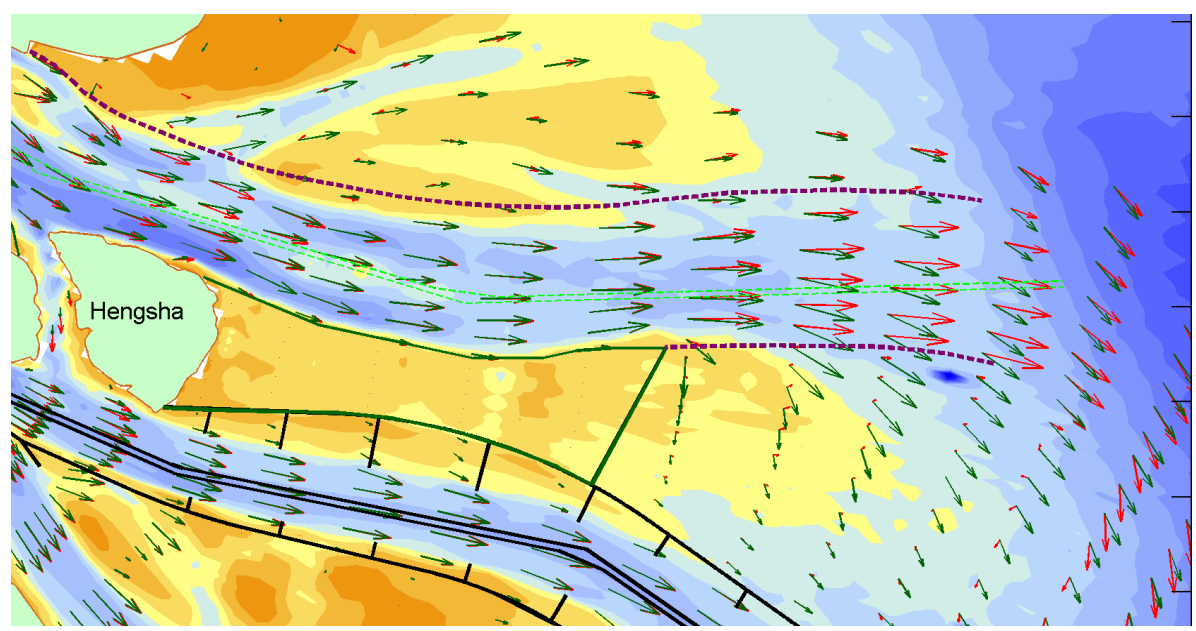

Figure 16. Ebb max. flow field: Reference and Configuration 2

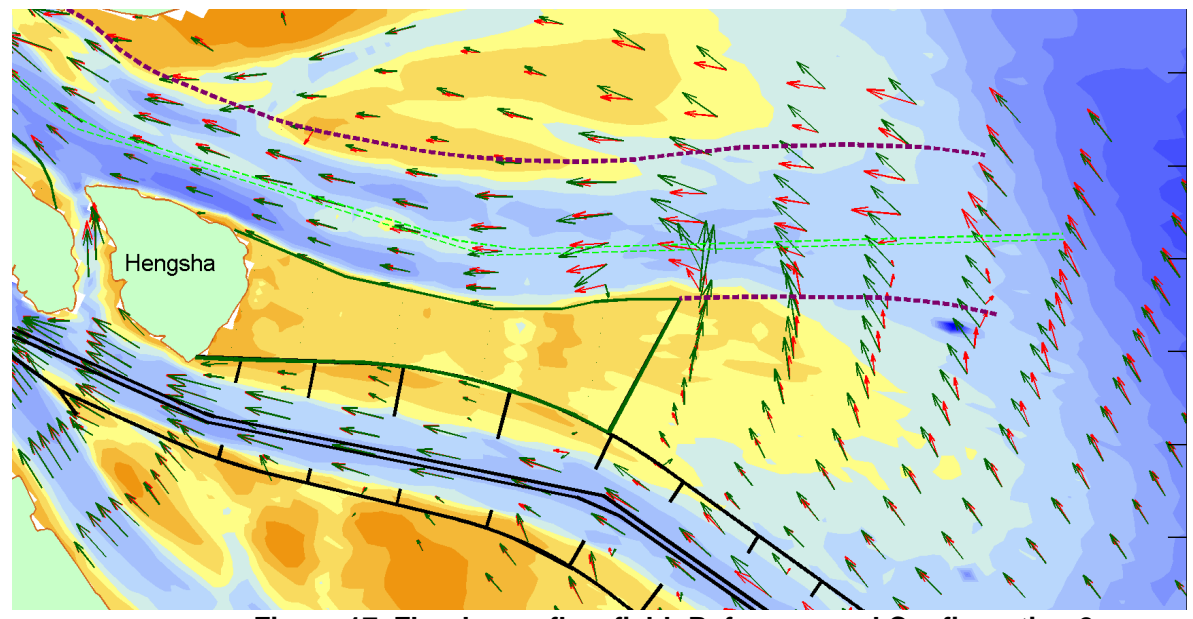

Figure 17. Flood max. flow field: Reference and Configuration 2

At the upstream, the ebb maximum velocity declines about $0.2 \mathrm{~m} / \mathrm{s}$ after implementation of the two training dikes. Given that there is a relatively deep channel in the upper reach (about $10 \mathrm{~m} \sim 15 \mathrm{~m}$ ), in order to improve the general condition of North Channel for navigation, it allows a little sedimentation at the upstream in early period of the project. After the project, with erosion at the downstream due to the increasing velocity, the flood discharge increases in North Channel thus the ebb discharge raises at 
the upstream of North Channel. The sedimentation in the upper reach will be reduced and expected to reach equilibrium.

From the above analysis, Configuration 2 produces relatively higher velocity at mouth bar area and the ebb maximum velocity takes place at the location lower than MSL $(+2.0 \mathrm{~m})$, thus Configuration 2 is chosen for further comparison.

\section{(2) Reference Configuration and Configuration 2, 4, 5 and 6}

From Fig 12 and Fig. 13, with the construction of groins along the channel, the resistance is further increased inside North Channel, thus the LWL is increased and the tidal range is declined. Compared with Configuration 2, the tidal range in Configuration 4 decreases about $7 \mathrm{~cm}, 11 \mathrm{~cm}$ and $14 \mathrm{~cm}$ respectively at Shidongkou, Liuxiao and Gongqiyu.

The groins further decrease the discharge distributed into North Channel and the discharge into South Channel is increased (Fig. 18). Compared to Reference Configuration and Configuration 2, Configuration 4 shows the ebb discharge in North Channel decrease by $10 \%$ and $4 \%$ respectively.

Configuration 4, 5 and 6 demonstrates the smaller widening rate of the channel leads to the less water distribution to the North Channel. But their difference is only about $3 \%$.

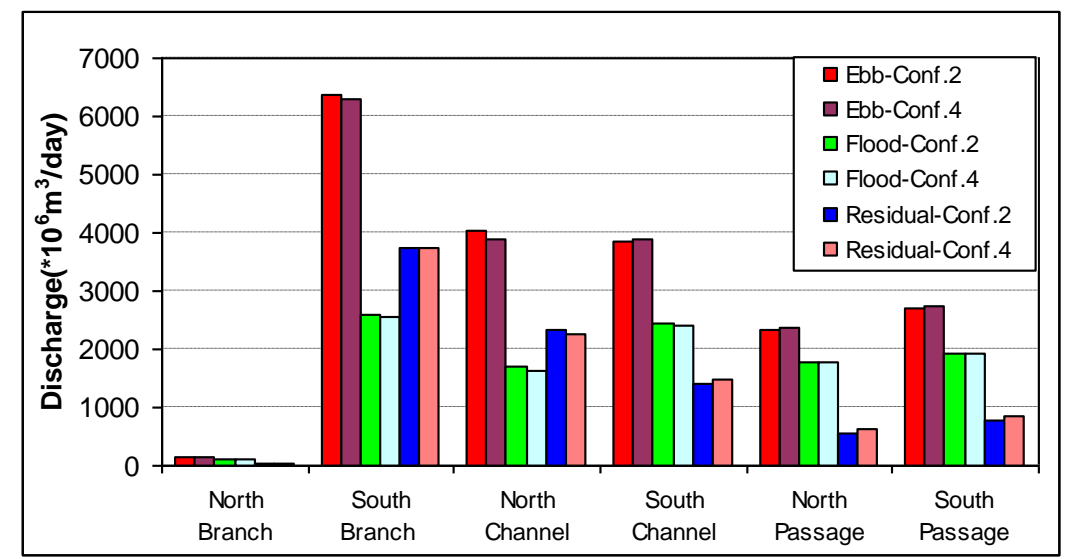

Figure 18. Flood, Ebb and Residual discharge distribution among the channels

Compared with Configuration 2, Configuration 4, 5 and 6 show that the ebb maximum velocity in the upper reach decreases about $0 \sim 0.1 \mathrm{~m} / \mathrm{s}$ with the reduction of the widening rate(Fig. 19), while in the lower reach (mouth bar area), on the contrary, the velocity increases about $0 \sim 0.2 \mathrm{~m} / \mathrm{s}$ due to the narrowing of the channel. The difference among Configuration 4, 5 and 6 is small. They have similar results. Configuration 6 has a relatively larger ebb velocity in the upstream and smaller one in the downstream. Configuration 4 gives the largest ebb velocity in mouth bar area.

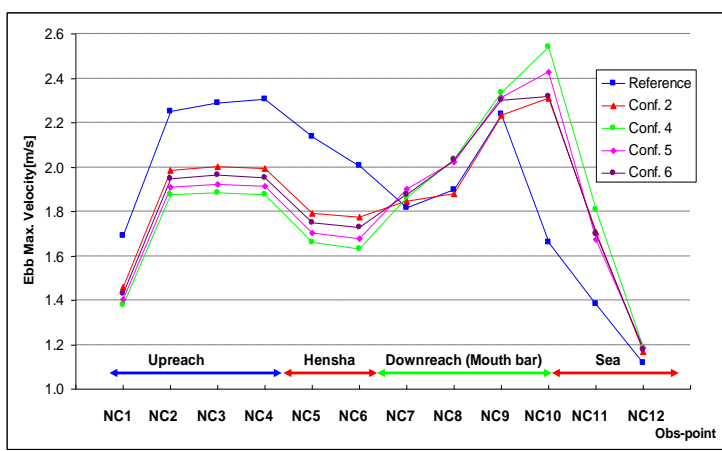

Figure 19. Ebb max. velocity along North Channel

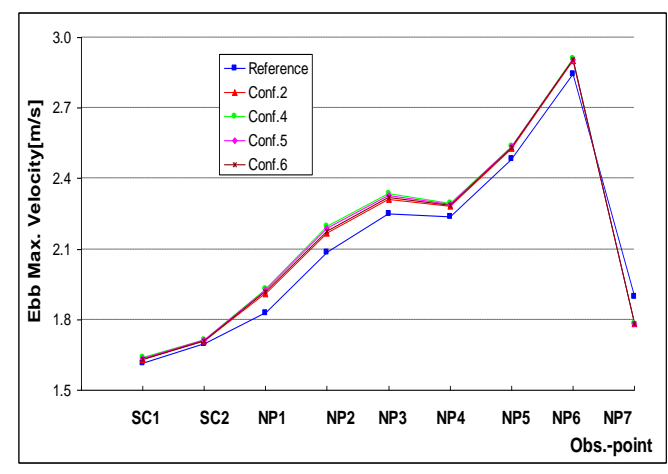

Figure 20. Ebb max. velocity along North Passage

The ebb maximum velocity is increased due to narrowing of North Channel and thus more discharge is distributed to the South Channel and North Passage (Fig. 20). The groins in North Channel 
will benefit maintenance of $12.5 \mathrm{~m}$ depth Navigation Channel in North Passage. From the above detailed analysis, engineering effects of different configurations can be summarized as below.

- In general, compared with Reference Configuration, regulating structures in North Channel increase resistance of the river reach, which leads to reduction of the flood discharge from the sea and decrease of the ebb discharge distributed to North Channel.

- Due to the fact that all of regulating structures are lower than $+3.0 \mathrm{~m}$, the tide wave which usually has HWL (High Water Level) larger than $+3.0 \mathrm{~m}$ can still propagate to Xuliujing with similar high water level. The regulating structures along the North Channel increase the channel resistance, elevate the LWL and reduce the tidal range.

- The training dikes adjust the flow field. The flow current between the dikes is changed from rotating current to reversing current with a direction more parallel to the design navigation channel.

- All the Configurations have the same tendency that the ebb velocity is decreased in upper reach and increased in lower reach of North Channel.

- All the Configurations raise the ebb discharge distributed to South Channel and North Passage, which is beneficial to the navigation channel maintenance in North Passage.

- Configuration 1,2 and 3 suggest that $+2.0 \mathrm{~m}$ dike elevation produces favourable ebb velocity and discharge at mouth bar area, and is also more economic than $+3.0 \mathrm{~m}$.

- Configuration 4, 5 and 6 suggest that smaller widening rate and narrower channel contributes to higher velocity near mouth bar area. But consequently, the velocity in the upper reach decreases.

Based on the above analysis, Reference Configuration, Configuration 2 and Configuration 4 are chosen for the further study in the morphological modelling with following considerations:

- Configuration 2 is chosen to simulate the morphological processes with the aim to investigate the influence if there are only two training dikes.

- The acceptable decreasing range of ebb velocity in the upper reach after regulating is not well known. Thus Configuration 4 which produces the lowest ebb maximum velocity in upper reach and highest ebb velocity near the mouth bar area is chosen for the further study in the morphological model. If the sedimentation in the upper reach is not acceptable, then a higher widening rate would be recommended.

\section{Morphological Model Simulation}

Due to the fact that the bed material of Yangtze Estuary is mainly composed of fine silt and clay, and the mechanism governing silt erosion, movement and sedimentation is still not well formulated in the morphological model. In this study, the morphological model was set up to show and analyse the morphological evolution of the river bed qualitatively. The $2 \mathrm{D}$ morphological model in which morphodynamic evolution techniques are implemented was set up and calibrated using measured bathymetry data. The results show that although the model has limitation on accurate simulation of the SSC in Estuarine Turbidity Maximum (ETM) area, it has capability of simulating erosion and sedimentation pattern of the estuary, thus it can be used for further study.

The morphological change after two year are simulated by the model with scenarios of Reference Configuration, Configuration 2 and Configuration 4. The differences of erosion and sedimentation between Configuration 2 and Configuration 4 are shown in Fig. 21. Comparing the results of the different Configurations, the following conclusions can be drawn.

- The morphological evolution shows a strong correlation with flow field simulated by the flow model. The morphological changes qualitatively reflect the changes of flow field under different configurations.

- Compared with the Reference Configuration, the regulating structures along the North Channel are beneficial to the channel regulation in North Channel. All the configurations can improve the flow field in mouth bar area and some erosion takes place in the area.

- The regulation works in North Channel benefit the channel maintenance in adjacent North Passage.

- The influence of the regulating structures is relatively small. The erosion and sedimentation are slow. More morphological time is needed to fully explore the function of the regulating structures.

- Compared with Configuration 2, Configuration 4 has more sedimentation in the groins field while has more erosion in mouth bar area.

- In Configuration 4 the groins increase the resistances of the lower reach of North Channel. The flow velocity at the upstream further declines, which results in more sedimentation. 
- From viewpoint of regulating mouth bar area, Configuration 4 seems to have more favourable effects than other configurations. Configuration 4 has more erosion in this area. Thus Configuration 4 is recommended as the optimal Configuration.

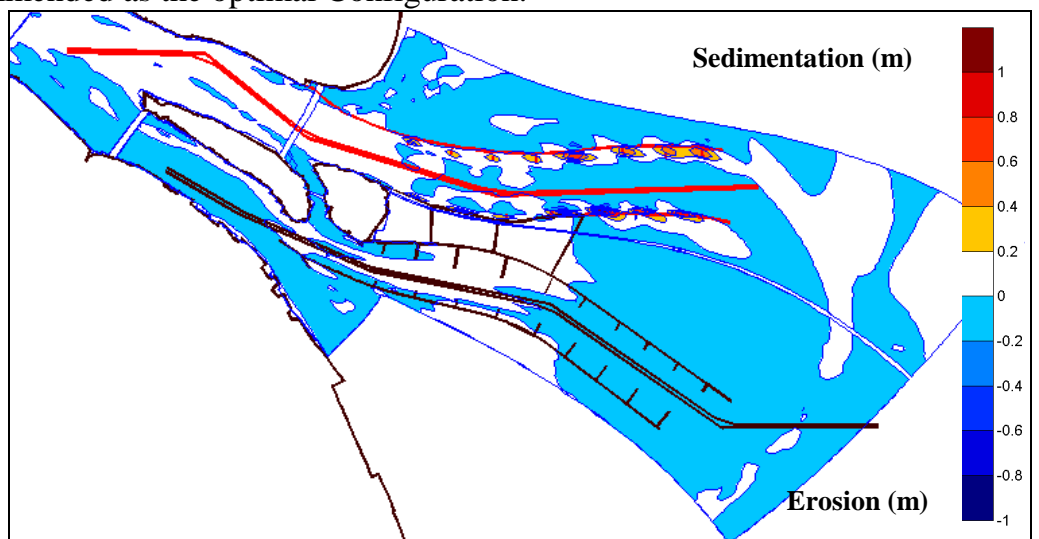

Figure 21. Cumulative Erosion/Sedimentation Difference: Configuration 4- Configuration 2

\section{DISCUSSION AND CONCLUSIONS}

Based on the analysis of historical and recent morphological evolution of North Channel, different configurations were proposed, and simulated by numerical flow and morphological model. Their modelling results are compared. Important conclusions drawn from this study are as follows.

- Yangtze Estuary is characterized of abundant river runoff and sediment load, median tidal range but with large tidal prism. These factors and effect of Coriolis force mainly control the morphological evolution of Yangtze Estuary and especially the large flood in the summer season plays a significant role.

- The basic regime of three-stage bifurcation, four-river mouth split of Yangtze Estuary is shaped under specific conditions (nature evolution and human interferences).general river regime will keep stable for a long time.

- With the formation of the river bank and completion of river regime stabilisation works, the morphological evolution of Yangtze Estuary is relatively in equilibrium. Regulation works can be undertaken in the North Channel before regulating the upper reach at South Branch.

- The regulation works in North Passage give a good example for channel regulation. Some basic principles could be adopted and adapted in the regulation works in North Channel.

- Regulating structures integrated with channel dredging are recommended for the channel regulation works in North Channel.

- Flow modelling results show that two training dikes tend to guide the main ebb and flood current inside the channel, increase the flow field at the mouth bar area. The regulation in North Channel would raise the ebb discharge distributed to South Channel and North Passage, which is beneficial to the navigation channel maintenance in North Passage.

- Configuration 4 seems to produce favourable flow field and largest erosion at the mouth bar area. It is therefore Configuration 4 is recommended as optimal Configuration for future studies.

Through the study, the following points are recommended to be considered in further studies:

- The impact of Zhongyansha Reservoir Work and Xinliuhesha Shoal Protection Works on the morphological evolution in upper-reach of North Channel need to be further analysed according to new measured data. A shoal protection works with geo-textile mattress structure along Baozhengsha is recommended, because the integrity of the shoal can stabilize the thalweg of upperreach and maintain the depth of the main channel.

- In the past century, the relationship between the tidal prism and the cross-section area of the tidal basins and estuaries were extensively studied. LeConte(1905), O'Brien $(1931,1969)$ and Jarret(1976) etc. found some basic relationships between the tidal prism and the cross-section area. Most of the findings can be represented by the general formulation:

$$
A=C P^{n}
$$


Where:

A : characteristic cross sectional area, $\mathrm{m}^{2}$

C: constant, unit depending on ' $n$ '

P: tidal prism, $\mathrm{m}^{3}$

In this study, it also reveals that there is also a good relationship between the tidal prism and the cross-section area in Yangtze Estuary (not be included in this paper). The relationship of A-P in Yangtze Estuary is primarily derived and established as:

$$
A=5.367 * 10^{-4} P^{0.90} \text {, with R-squared value of } 0.92
$$

Therefore in future study of regulating works in North Channel, it should be kept in mind that the regulation works should not significantly decrease the tidal prism of the upstream. The reduction of tidal prism will result in sedimentation at the upstream (South Branch) and deteriorate the channel conditions.

- A submerged dike with lower elevation is suggested to be built in Chongming Gully. This would benefit the Chinese Sturgeon migration from the sea to river and increase of the tidal prism at the upstream.

- The construction scale of regulating structures in North Channel should be balanced with its influence on tide prism of the upstream. The elevation of dikes and groins, length of groins and elevation of Chongming Gully submerged dike, etc. should be very well elaborated.

- In accordance with the Planning of Reclamation of Hensha East Shoal, none of groins along North bank of reclamation area are needed in order to obtain more deepwater shoreline.

- In order to break through the mouth bar and maintain the channel with acceptable dredging volume, widening rate along the channel should be carefully demonstrated. The successful experience from regulation in North Passage indicates that the widening rate along mouth bar area could be negative.

- Due to complexity of the natural system, accurate simulation of the ETM formation and the interaction between flow and sediment is still quite difficult. The accuracy of the simulation of morphological processes needs to be improved.

\section{ACKNOWLEDGEMENT}

The authors wish to acknowledge the financial support of the Yangtze Estuary Waterway Administration Bureau (YEWAB) in China as well as the National Institute for Coastal and Marine Management (Rijkswaterstaat/RIKZ) in The Netherlands.

This study is carried out within the framework of the UNESCO-IHE Partnership Research Fund (UPaRF) which is partly funded by the Dutch Ministry of Foreign Affairs (DGIS) under the Project Sediment and Sediment Transport from Reservoirs to Estuaries (RESEDUE).

\section{REFERENCES}

Fan Q.J., L. Jin, Y.H Cai and M. Gao, 2006. General report Integral Techniques of Deep Water Channel Regulation Project in Yangtze Estuary. Yangtze Estuary Waterway Administration Bureau.

Jarrett, J.T., 1976. GITI report no. 3., Tidal prism-inlet area relationships. Coastal Engineering, Research Center, US Army Corps of Engineers, Fort Belvoir, VA, USA

LeConte, L.J., 1905. Discussion on the paper, "Notes on the improvement of river and harbor outlets in the United States" by D. A. Watt, paper no. 1009. Trans. ASCE 55 (December): 306-308

O’Brien, M.P., 1931. Civil Engineering .Estuary and Tidal Prisms Related to Entrance Areas. 1 (8): 738-739.

O’Brien, M.P., 1969. J Waterway Port Coast Ocean Eng, Equilibrium flow areas of inlets on sandy coasts. 95 (1): $43-52$

Roelvink J.A., 2006. Coastal Engineering, Coastal Morphodynamic Evolution Techniques. 53277 287.

Tan Z.W., Q.J. Fan, M. Gao and W.Y Zheng, 2009. $14^{\text {th }}$ China Ocean and Coastal Engineering Congress, New development on the research of navigation channel regulation in Yangtze Estuary. 891-900 